\title{
The Effect of Translators' Learning Style on Translation Quality of Expressive Texts
}

\author{
Amin Karimnia \\ Islamic Azad University, Fasa Branch, Fars, Iran
}

Soulmaz Afshari

Islamic Azad University, Fars Science and Research Branch, Iran

\section{Introduction}

Throughout history, written and spoken translation has had a crucial role in communication between people not solely as a way to access important texts with religious purposes (Munday, 2008). Translation studies have become a noteworthy movement during the past thirty years. Since translation is a newly-born academic major, there is no translation theory that all translators can apply in their own practices, so translation studies have been controversial from various viewpoints, such as the debate on what constitutes a good translation (Matrat, 1992 as cited in Iida, 2008).

As Robinson (1997) points out, translation and language learning are highly interrelated, so he believes that translation is actually a language learning process and the translator is always a language learner. In this way, many factors that affect language learning can affect translation learning, such as gender, culture, and learning style.

Learning style is the way in which our minds and bodies gather information from everything around us. When we are trying to learn it helps us know how our brains work. Similarly, the awareness of learning style helps us recognize our strength and maximize it so as to have better life in our work and our leisure time (Brown, 2007).

Different language experts introduced different learning-style classifications, for instance Felder and Soloman (2006). They believe people are divided into eight groups according to their learning styles, namely reflective, active, sensing, intuitive, visual, verbal, global, and sequential. They test these styles on people 
who learn different subjects of science and arts, such as learning languages, physics, or mathematics but they did not apply it to people who learn how to translate accurately.

Translation is a vast area that includes different aspects. A translator should consider many different factors when he is trying to translate. These factors are text type, the writer, the reader, source language, target language (Munday, 2008).

Reiss (1977/89) has introduced three text types: operative, expressive, and informative.

Informative texts convey information and knowledge such as lectures, and tourist brochures. Expressive texts stress the aesthetic values and the semantic content such as novels, short stories, and poems. Operative texts enable the reader to receive the exact meaning of the writer such as sermons, and advertisements.

The present study seeks to investigate the effect of learning styles on translation quality in of expressive texts. The main purpose was to indicate those learning styles which had an impact on translation quality and the interaction of learning style and proficiency level in translation quality of expressive texts.

\section{Method}

\subsection{Participants}

Sixty translators working in translation centers in Shiraz participated in this study. But just 52 of them answered the questionnaire properly and completed the task of translation. Participants consist of female and male B.A. graduates in English translation. To determine their proficiency level, Oxford Quick Placement (2004) tests were administered. Then, they answered Felder's (2006) Learning Style Questionnaire and, finally, they were asked to translate a paragraph of expressive text to determine their translation quality. Based on the participants' response to Felder's (2006) Learning Style Questionnaire, they were categorized by the researchers into 8 groups. Since the number of participants for each learning style was insufficient and due to the practical considerations of the study, the researchers decided to study the effect of sensing and visual learning styles on the translation quality of expressive texts. 


\subsection{Data Collection Procedure}

In the initial step, the Oxford Quick Placement Test was administered to the participants. The participants did the test in 35 minutes. After a five-minute interval the second questionnaire, i.e. Felder's (2006) Learning Style questionnaire was given to the participants who were asked to solve it in 20 minutes. Then, the participants received a paragraph in English intended for translation into Persian. They were also provided with a glossary containing the Persian meaning of difficult words. The participants were asked to read the paragraph and translate it carefully. Based on a pilot study done by the researchers, the participants were given 30 minutes to translate the text.

Three translation experts rated the participants' translation according to HubscherDavidson's (2009) assessment scale.

\subsection{Data Analysis Procedure}

The data collected from the above-mentioned test, questionnaire, and text translation were transferred to SPSS, version 18, for statistical analysis. The participants were divided into two groups, sensing and visual, based on their answers to the Felder (2006) learning style questionnaire. Then, the researchers used t-test to find out the relationships between learning styles and translation quality of expressive texts.

As mentioned earlier, the translated text was rated by three translation experts based on the seven items/elements of the scale introduced by Hubscher-Davidson (2009). The scale includes 1. Stylistic features, e.g. register; 2. Vocabulary; 3. Grammar; 4. Idioms; 5. Cultural features; 6. Imagery/ expressions; 7. Overall coherence of translation. Final results were computed out of 100 for each translation. In order to examine the inter-rater reliability between the raters' marks the researchers employed Pearson's Correlation method.

Finally, a two- way ANOVA was run to check the effect of translators' proficiency level and its interaction with learning styles in translating expressive texts. 


\section{Results}

As explained in earlier parts, 52 translators who were working in translation centers in Shiraz participated in this study. All participants answered the Felder (2006) learning style questionnaire and, on the basis of the result they were divided into eight groups of active, reflective, sensing, intuitive, visual, verbal, global, and sequential learners. As it was explained in the previous section, the sensing and visual groups were selected due to their population.Then, the participants took the Oxford Quick Placement Test and after that translated an English expressive paragraph into Persian.

The participants' translations were rated by three translation experts based on Hubscher- Davidson (2009) assessment scale. In order to insure the inter-rater reliability, the raters' marks of participants' translations were analyzed through Pearson's Correlation. The result is shown in Table 1.

Table 1: Correlation Between Raters’ Marks

\begin{tabular}{|ll|c|c|c|}
\hline & & Rater1 & Rater2 & Rater3 \\
\hline \multirow{2}{*}{ Rater1 } & Pearson Correlation & 1 & .427 & .673 \\
& Sig. (2-tailed) & & .015 & .000 \\
& $\mathrm{~N}$ & 32 & 32 & 32 \\
\hline \multirow{2}{*}{ Rater2 } & Pearson Correlation & .427 & 1 & .826 \\
& Sig. (2-tailed) & .015 & & .000 \\
& $\mathrm{~N}$ & 32 & 32 & 32 \\
\hline \multirow{2}{*}{ Rater3 } & Pearson Correlation & .673 & .816 & 1 \\
& Sig.(2-tailed) & .000 & .000 & \\
& $\mathrm{~N}$ & 32 & 32 & 32 \\
\hline
\end{tabular}

*. Correlation is significant at the 0.05 level (2-tailed)

Table 2 shows the mean of sensing and visual scores are different but this difference cannot show that they are really different in their performances in translating the expressive texts. 
Table 2

Group Statistics of sensing and visual participants

\begin{tabular}{|c|c|c|c|c|}
\hline SV & $\mathrm{N}$ & Mean & Std. Deviation & $\begin{array}{c}\text { Std. Error } \\
\text { Mean }\end{array}$ \\
\hline rater1 sensing & 17 & 76.88 & 4.923 & 1.194 \\
visual & 15 & 71.40 & 2.324 & .600 \\
\hline
\end{tabular}

In order to find out the difference between participants' performances (sensing and visual) in translating expressive texts the researchers employed the Independent ttest. Table 3 indicates that sensing participants have better performance in translating expressive texts.

Table 3: Independent t-test of sensing and visual participants' performances in translating expressive texts

\begin{tabular}{|l|c|c|c|c|c|c|c|}
\hline & \multicolumn{2}{|l|}{$\begin{array}{l}\text { Levene's test for } \\
\text { equality of } \\
\text { variances }\end{array}$} & \multicolumn{5}{l|}{ t-test for equality of means } \\
\hline $\begin{array}{l}\text { Rater1 equal variances } \\
\text { assumed/equal } \\
\text { variances not assumed }\end{array}$ & $\mathrm{F}$ & Sig. & $\mathrm{T}$ & $\mathrm{df}$ & $\begin{array}{c}\text { Sig. } \\
\text { 2tailed }\end{array}$ & $\begin{array}{l}\text { Mea } \\
\mathrm{n} \\
\text { differ } \\
\text { ences }\end{array}$ & $\begin{array}{c}\text { std. } \\
\text { error } \\
\text { differe }\end{array}$ \\
\hline & 12.338 & .001 & 3.938 & 30 & .000 & 5.48 & 1.392 \\
2 & 4.103 & 23.39 & .000 & 6 & & 5.48 \\
2
\end{tabular}

A two-way ANOVA was run to examine whether the interaction of proficiency and learning style is significant in translating expressive texts or not. Table 4 reveals that neither proficiency level nor interaction of proficiency and learning style in translating expressive texts is significant. 
Table 4: Two-way ANOVA comparing the participants' translations and their proficiency level

\begin{tabular}{|c|c|c|c|c|c|}
\hline Source & $\begin{array}{c}\text { Type III sum } \\
\text { of squares }\end{array}$ & Df & Mean square & F & Sig. \\
\hline $\begin{array}{c}\text { Corrected } \\
\text { Model }\end{array}$ & $548.208^{\mathrm{a}}$ & 22 & 24.919 & 1.450 & .289 \\
\hline Intercept & 143160.962 & 1 & 143160.962 & 8330.487 & .000 \\
\hline prof & 243.721 & 17 & 14.337 & .834 & .643 \\
\hline SV & 203.363 & 1 & 203.363 & 11.834 & .007 \\
\hline prof * SV & 51.342 & 4 & 12.836 & .747 & .584 \\
\hline Error & 154.667 & 9 & 17.185 & & \\
\hline Total & 177418.000 & 32 & & & \\
\hline $\begin{array}{c}\text { Corrected } \\
\text { Total }\end{array}$ & 702.875 & 31 & & & \\
\hline
\end{tabular}

a. $\quad$ R Squared=.780 ( Adjusted R Squared=.242)

\section{Discussion and Conclusion}

Translation experts such as Robinson (1997) believe that many factors affect translation quality for instance gender, experience and many other individual differences. Here, it is clear that learning style is also an effective factor in translation quality.

As the results in Table 3 indicate, there is a high correlation between sensing translators' performances and the quality of their translation in case of expressive texts. And Based on the information in Table 4, the interaction between translators' proficiency level and their learning style is not a significant factor in translating expressive texts. 
We can thus conclude that other characteristics of sensing translators may help them present more acceptable translations than others in a way that the role of proficiency is faded. These characteristics - mentioned by some experts such as Felder and Soloman (2006) and Robinson (1997) - refer to being patient, careful, practical and paying attention to facts and details.

Iida (2008) conducted a research on the impact of experience on translation quality and the result revealed that those participants with more experience in speaking English and living in an English-speaking country performed better translations because they used more natural words and meanings in the production of translation. Iida (2008) believes that experience is one of the most important factors in translation processes and translation products. In the same line, the present study supported the idea that individual differences are important factors in translation products and one of these differences is the translator's learning style. As shown in this study, sensing learning styles can be effective in translating expressive texts, so it can be concluded that different learning styles can help translators in translating different text types of different qualities.

The present study also has some implications for teaching translation. As translation is a newly-born major in our country, Iran, and in the world, teaching translation is a hard and delicate task. This study suggests that the learning style is an important factor in translation and plays an effective role in translating expressive texts. So, this result can help translation teachers to awake this learning style in their students by giving them suitable exercises and making them ready to produce a better translation of expressive texts.

According to the result of this study, translation teachers should study different learning styles more attentively and find out which style is effective in translating other text types. The final result is that their translation qualification can be improved day by day.

Since translation is not an old major in our country and in the world, it is a hard and delicate task. This study suggests that learning style is an important factor in translation. According to the present study sensing learning style plays a significant role in translating expressive texts. The result of the present study can help translation teachers to awake this learning style in their students by giving them suitable exercise and make them ready to have a better translation of expressive texts. 


\section{References and notes:}

Brown, H. D. (2007). Styles and strategies. In T. M. Cataldo (5 ${ }^{\text {th }}$ ed.), Principles of language learning and teaching (pp. 118-150). United States of America: Pearson Education.

Felder, R. (2006). Learning style questionnaire. Retrieved January 2012, from http://www.engr.ncsu.edu

Felder, R., \& Soloman, B. (2006). Learning styles and strategies. Retrieved January 2012, from http://www.engr.ncsu.edu

Hubscher-Davidson, S. (2009). Personal diversity and diverse personalities in translation: A study of individual differences. Perspectives: Studies in Translatology, 17 (3), 175192.

Iida, J. (2008). Individual differences in translation process. Translation Journal. Retrieved November 2012, from http://www.translationjournal.com

Munday, J. (2008,). Introducing translation studies: Theories and applications. London and New York: Routledge.

Reiss, K. (1977/89). Text types, translation types, and translation assessment (pp. 105115). Translated by A. Chesterman. In A. Chesterman (Ed.), (1989).

Robinson, D. (1997). The translator as a learner. Becoming a translator (pp. 47-91). New York: Routledge.

\section{SUMMARY}

\section{The Effect of Translators' Learning Style on Translation Quality of Expressive Texts}

\section{Amin Karimnia}

Islamic Azad University, Fasa Branch, Fars, Iran

\section{Soulmaz Afshari}

Islamic Azad University, Fars Science and Research Branch, Iran

The purpose of the present study was to investigate if translators' learning style and the interaction of translator's learning styles and proficiency level affect the translation quality of expressive texts. Participants included 52 translators who worked in translation centers in Shiraz. The elicitation instruments used for data collection were (a) an Oxford Quick Placement Test, used to measure the participants' proficiency level, (b) the Felder (2006) learning style questionnaire, to find out the participants' learning styles, and (c) a paragraph of expressive text which was translated to determine the quality of participants' translations. Pearson's correlation, t-test and two-way ANOVA procedures were used to analyze the data. The results revealed that translators' learning styles significantly affect their quality of translation in that sensing translators outperformed visual ones. However, the interaction of learning style and proficiency level did not prove to be to be significant. Based on the results obtained, some suggestions were made.

\section{Keywords: Translation quality, expressive texts, learning style, translators}

